
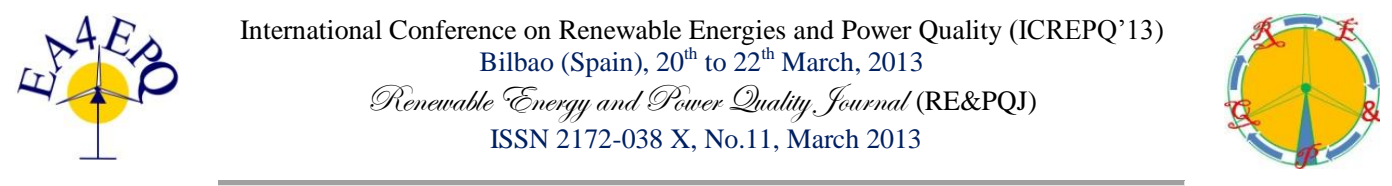

\title{
Porous Ni Electrodes for Hydrogen Production from Water Electrolysis
}

\author{
I. D. Savaris ${ }^{1}$, C. S. Torres ${ }^{1}$, A. M. Sheikh ${ }^{1}$, F. Weschenfelder ${ }^{2}$, L. Schaeffer ${ }^{2}$ and C. Malfatti $^{1}$
}

\author{
${ }^{1}$ Metallurgical Department (DEMET), Pros-graduation Programme in Mining Metallurgical and Materials \\ Laboratory of Corrosion Research (LAPEC) \\ Federal University of Rio Grande do Sul (UFRGS) \\ Av. Bento Gonçalves, 9500 - 91501-970 - Porto Alegre/RS, Brazil \\ Phone number:+0055 51 33089539, e-mail: isra.savaris@gmail.com, camila.torres@ufrgs.br, \\ ahmad.elsheikh@hotmail.com, celia.malfatti@ufrgs.br
${ }^{2}$ Metallurgical Department (DEMET), Pros-graduation Programm in Mining Metallurgical and Materials Metal Forming Laboratory (LdTM)
Federal University of Rio Grande do Sul (UFRGS)
Av. Bento Gonçalves, 9500 - 91501-970 - Porto Alegre/RS, Brazil
Phone number:+0055 51 33086134, e-mail: franciele.weschenfelder@ufrgs.br, schaefer@ufrgs.br

\begin{abstract}
Hydrogen has been seen as one of the most valuable options regarding renewable energy storage and conversion. However, its production is still mostly based on fossil fuels, in part because of the high cost of alternative production routes, as is the case of water electrolysis for example. This fact is explained by the energy consumed during the process of hydrogen evolution from water. Nevertheless, the research on water electrolysis is justifiable by the advantages that the process offers, as high produced hydrogen purity, possible association with other renewable energy sources such as solar, hydro and wind power generation, no $\mathrm{CO}_{2}$ emissions during the evolution, simplicity of the process, as so many others. With the purpose of increasing the hydrogen-producing device (electrolysers) performance, great scientific efforts have been directed to the electrodes base materials and their surface technology. In this way, the present work propose powder metallurgy based processes as production routes of nickel porous electrodes, i.e., relatively low cost and high active superficial area electrodes for hydrogen production.
\end{abstract}

\section{Key words}

Hydrogen, electrolysis, powder metallurgy, porous electrodes, catalytic activity.

\section{Introduction}

The world energy production model is in its majority based on fossil fuels. However, with the increasing environmental concerns related to carbon dioxide $\left(\mathrm{CO}_{2}\right)$ emissions and fossil fuels shortage, the search for alternative energy resources has been intensified [1, 2, 3].
Any analysis of the current energy world scenario draws on the combination of energy efficiency improvement and the use of renewable-type energies. The industrial use of renewable energies is not still well established as they present several problems that generate insecurity in this sector [4].

The hydrogen $\left(\mathrm{H}_{2}\right)$, in this context, has attracted the attention of new researches due to both the viability of environmentally benign routes of production and the possibility of energy conversion using fuel cells, a process in which no harmful emissions occur. Additionally to the possible usage as energy carrier, hydrogen may serve as an industry raw material, especially in petroleum refineries, ammonium and methanol production $[1,5]$.

A variety of processes can be employed on the hydrogen obtainment, being them classified according to their source. Currently, more than $50 \%$ of the hydrogen produced derives from natural gas reforming, being that the great majority of the remnant sources are also derivatives from fossil fuels. For this reason the production of hydrogen become, in the most part, an indirect source of $\mathrm{CO}_{2}[6]$.

Another possibility for hydrogen production could be the water electrolysis, knowing that for this purpose, the research related to the used electrolytic cell efficiency is of great importance, due to the fact that this is the most energetically expensive $\mathrm{H}_{2}$ production process [5]. 
In an electrolytic cell, the equilibrium or reversible potential needed for $\mathrm{H}_{2}$ production via water electrolysis, namely, the ideal potential associated with $\mathrm{H}_{2}$ regardless resistive losses, is of $1.23 \mathrm{~V}$ at $25^{\circ} \mathrm{C}$ and the minimum amount of energy required is about $+273.2 \mathrm{~kJ} \mathrm{~mol}^{-1}$. Nevertheless, considering the previously mentioned losses, the real cell demanded potential goes up to $1.8-2.0 \mathrm{~V}$ along with a current density of 1000-300 A.m ${ }^{-2}$ [7].

For this reason, in order to turn the water electrolysis into a more efficient process, the technology related to the development of electrodes for $\mathrm{H}_{2}$ evolution has been the core of many studies, aiming among others, to increase the active area and to evaluate lower cost materials for their fabrication.

In kinetic terms, choosing the materials for electrodes fabrication, in the case of hydrogen, the cathode, is of capital importance, considering that the reaction rate of $\mathrm{H}_{2}$ reduction is also directly determined by the cell overpotential. The overpotential depends on many different factors, among which, the most important could be said to be the activation energy needed for the reduction reaction to occur. The activation energy may be strictly related to the electrode constitutional material and superficial configuration [7].

In this way, an increase on the superficial area available for the hydrogen reduction reaction and the selection of a material with high catalytic activity, by way of explanation, activation energy sufficiently low, are essential measures to be taken in order to have a performance increase $[8,9]$.

For the hydrogen production from water, metallic electrodes are normally employed. Among the materials of possible usage, the noble metals, such as platinum, are comparatively the ones that show higher catalytic activity. However, seeking to turn the water electrolysis into a more economically viable process, the employment of less expensive metals has been studied.

For this purpose, nickel (Ni) and its alloys have being regarded as valuable options due to their high electro catalytic activity in alkaline media, as well as composite materials, especially metal-polymeric composites have been extensively verified for catalytic applications [10, 11, 12].

Nickel powders having a highly irregular filamentary shape can be fabricated and sintered to produce highly porous structures, which are in high demand for battery, catalyst and filter materials applications. In addition to high porosity these materials offer excellent corrosion resistance and good electrical conductivity [13].

In this work, metallic $\mathrm{Ni}$ electrodes were produced via powder metallurgy $(\mathrm{P} / \mathrm{M})$, by this route, high active superficial area may be obtained, associating then, beneficial electrochemical properties with a technically simple and relatively inexpensive process, thereby representing options favorable to technological transfer [14].
By way of comparison, dense Ni electrodes were also produced by electrodeposition, promoting thus the possibility of evaluation and comparison of a porous morphology front a non porous, i.e., dense ones.

\section{Experimental}

\section{A. Sample production}

A preliminary comparative evaluation between the parameters used in the electrodes production (samples) was held aiming to select and optimize the process. For this, representative samples of metallic $\mathrm{Ni}$ were produced, in different pre-sintering processing conditions, varying the compacting pressures $(85 \mathrm{Mpa}$ and $106 \mathrm{Mpa}$ ), named NS1 and NS2 respectively. The pressings of the samples were performed by the conventional cold pressing with the utilization of a molding press BONEVAU model P30 ST. The sintering was performed at a temperature of $1090^{\circ} \mathrm{C}$ for $1 \mathrm{~h}$ with a heating rate of $10^{\circ} \mathrm{C} \cdot \mathrm{min}^{-1}$ and an isothermal hold of 30 $\min$ at $500^{\circ} \mathrm{C}$ in an $\operatorname{argon}(\mathrm{Ar})$ atmosphere.

The dense Ni electrodes, named NE, brought out by electrodeposition were produced at $50^{\circ} \mathrm{C}-55^{\circ} \mathrm{C}$ in a stirred nickel Watts bath solution for $20 \mathrm{~min}$ and current density of 0.04 A.cm ${ }^{-2}$.

\section{B. Morphological Characterization}

The characterization of the samples, regarding the morphology and structure were done focusing on their surface roughness, the analysis was carried out by quantitative analytical analysis such as profilometry, as well as, by qualitative visual analysis through scanning electron microscopy (SEM).

\section{Electrochemical tests}

The catalytic activities of the produced samples were measured by potentiodynamic polarization in alkaline media $(35 \mathrm{wt} \% \mathrm{KOH})$ at $25^{\circ} \mathrm{C}$ with sweep rate of $5 \mathrm{mV} . \mathrm{s}^{1}$ using a postenciostat PAR model 273, in order to reproduce the industrial hydrogen evolution process. For this reason, a conventional electrolytic cell was assembled, counting with a working electrode (Ni samples produced via powder metallurgy), a counter electrode (platinum wire) and a saturated calomel electrode (SCE) as the reference electrode. With this device, potentiodynamic polarization scans were performed and the obtained curves were analyzed.

\section{Results}

\section{A. Morphological Characterization}

The morphology studies exposed the relatively high porosity, which is related to the electrochemical active area of the samples produced by conventional cold pressing. The images obtained (Figure 1 and 2) show that is possible to obtain porous electrodes by powder metallurgy, suggesting that a superior electrochemical 
performance could be expected for the electrodes produced in specific conditions. Figure 3 shows the morphology of the Ni electrode obtained by electrodeposition.

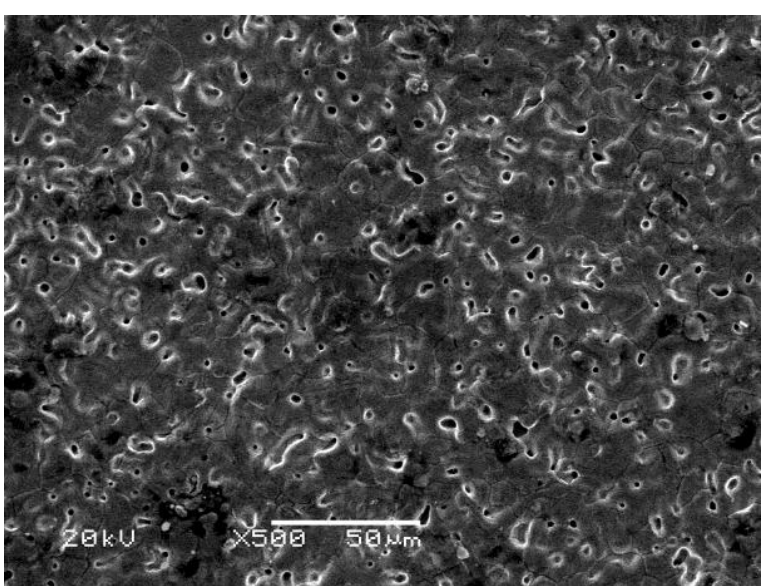

Figure 1: Scanning electron microscopy (SEM) of the NS1 electrode.

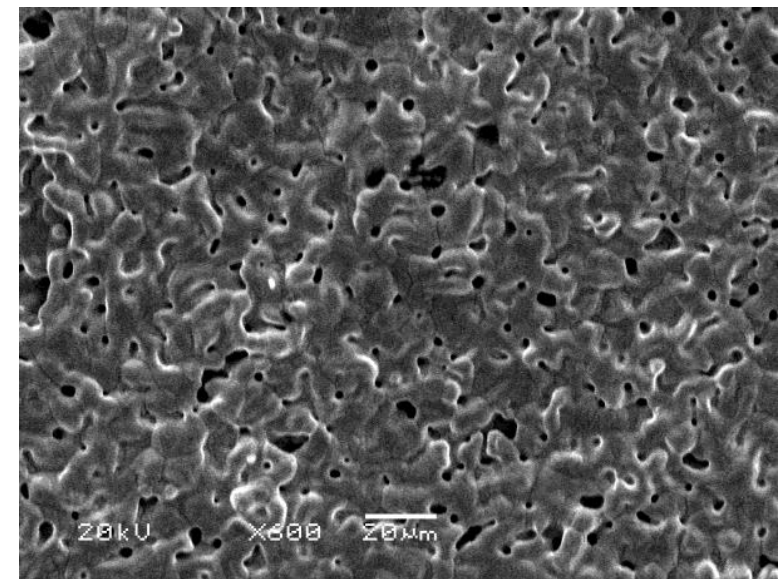

Figure 2: Scanning electron microscopy (SEM) of the NS2 electrode.

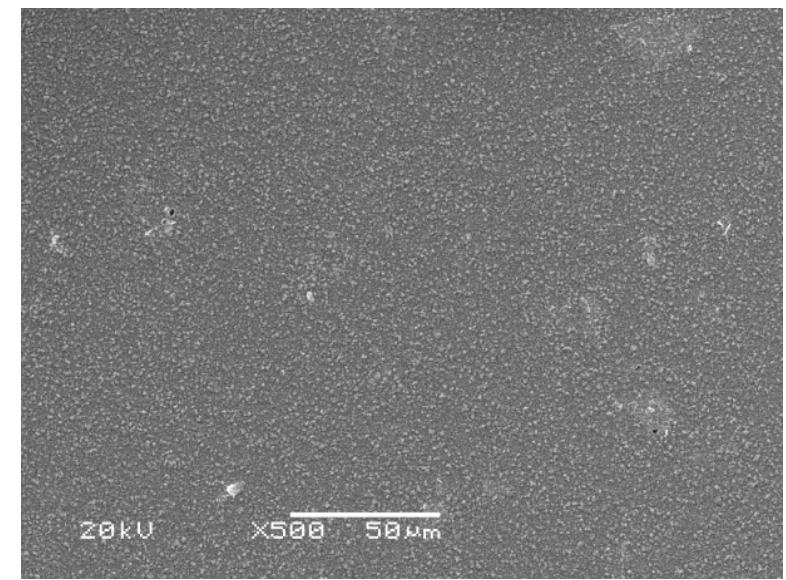

Figure 3: Scanning electron microscopy (SEM) of the NS2 electrode.

It may be easily seen the difference between the samples produced by the different processes, being that cold pressing process, as expected, produced electrodes with far higher porosity than the electrodeposition.
The images generated by perfilometry may be seen and compared in Figure 4.
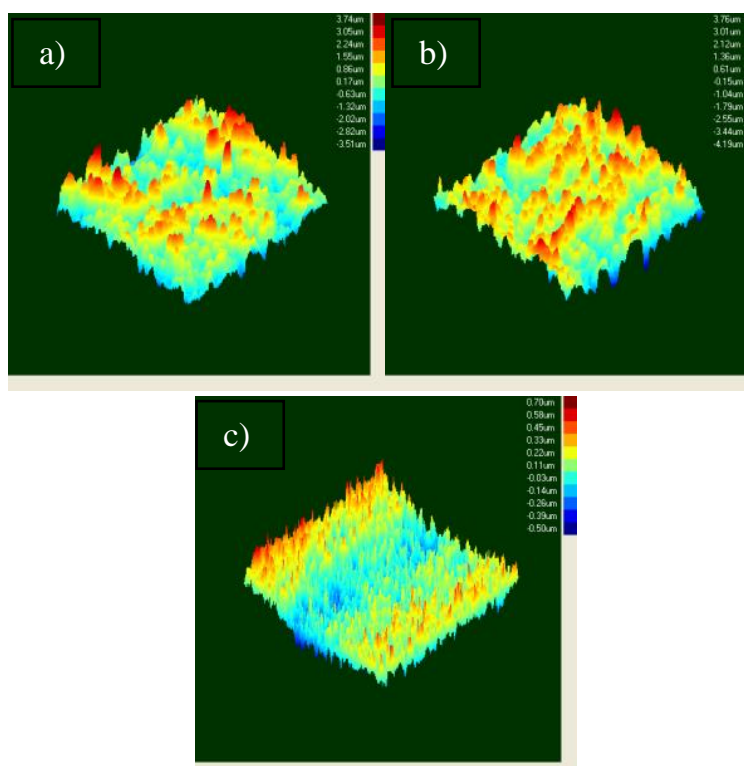

Figure 4: 3D images of a) NS1 and b) NS2 and c) NE surfaces obtained by perfilometry analysis.

The results obtained through the profilometry analysis (Fgure 4 Table 1) point roughness values relatively high, thus high catalytic activity associated, for both NS1 and NS2, when compared to NE. This suggests the possibility of porous electrodes production with high superficial area by a considerably more simple and cheap process front electrodeposition. The NS1 and NS2 electrode samples showed close roughness values ( $\mathrm{Ra}, \mathrm{Rms}$ and $\mathrm{Ry}$ ), what may be explained due to the small difference between the pressing pressures used in each sample. So, for comparison purposes between electrodes produced by powder metallurgy (pressing + sintering), which have as only variable the pressing pressures, larger differences in this parameter should be used in order to understand deeply its influence on the produced electrodes morphologies.

Table 1: Roughness values of NS1 NS2 obtained by profilometry analysis.

\begin{tabular}{c|c|c|c}
\hline $\begin{array}{c}\text { Samples/ } \\
\text { Roughness }\end{array}$ & $\begin{array}{c}\text { Ra } \\
(\mu \mathrm{m})\end{array}$ & $\begin{array}{c}\text { Rms } \\
(\mu \mathrm{m})\end{array}$ & $\begin{array}{c}\mathrm{Ry} \\
(\mu \mathrm{m})\end{array}$ \\
\hline NS1 & $0,72 \pm 0,05$ & $0.92 \pm 0,09$ & $5,64 \pm 1,55$ \\
\hline NS2 & $0,80 \pm 0,07$ & $0,99 \pm 0,10$ & $5,53 \pm 0,35$ \\
\hline NE & $0.05 \pm 0.006$ & $0.07 \pm 0.01$ & $0.54 \pm 0.20$ \\
\hline
\end{tabular}

\section{B. Electrochemical tests}

The polarization curves held in alkaline media (Figure 5) confirmed the improved behavior of the electrodes that presented higher porosity. Through the obtained curves it is possible to verify that both samples, NS1 and NS2, presented a lower cathodic overpotential when compared to $\mathrm{NE}$, being this result coherent with the higher active superficial area associated to the higher values of roughness measured and to the visually observed higher porosity as well. Comparatively, the results gathered for the NS1 and NS2 are too close, confirming the hypothesis of little variation on the superficial area 
evaluated by the profilometry tests due to the lack of difference between their pressing pressures.

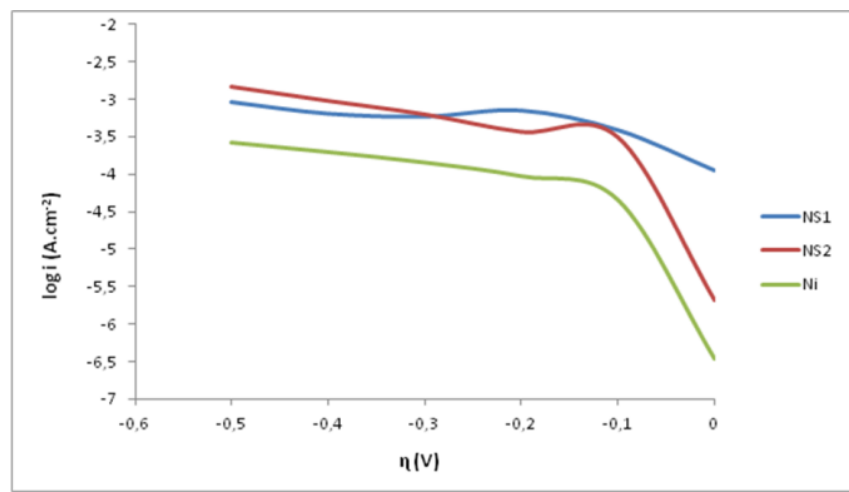

Figure 5: Polarization curves for NS1, NS2 and NE held in alkaline media $(35 \mathrm{wt} \% \mathrm{KOH})$.

\section{Conclusion}

The results demonstrate the possibility of porous $\mathrm{Ni}$ electrodes production by powder metallurgy, being that this process presents great advantages regarding its simplicity and low cost, mainly comparing it to the complex electrochemical obtaining processes. Electrochemical tests indicated the better performance of the more porous electrodes, i.e., produced by powder metallurgy, do not just show better fabrications conditions, but also preferred working ones, being that lower overpotentials signify lower energy expenses during the hydrogen production via water electrolysis

\section{Acknowledgement}

The present work was carried out with support of CAPES, Brazilian Government entity focused in human resources formation. The authors also would like to thank the financial support of Brazilian agencies: $\mathrm{CNPq}$ and FAPERGS.

\section{References}

[1] Turpeinen E., Raudaskoski R., Pongrácz E., Keiski R.L., Thermodynamic analysis of conversion of alternative hydrocarbon-based feedstocks to hydrogen. International Journal of Hydrogen Energy, 33 (2008) 6635-6643

[2] Pereira A. O., Soares J. B., Oliveira R. G.,; de Queiroz R. P. Energy in Brazil: Toward sustainable development? Energy Policy, 2008, Vol.36(1), pp.73-83.
[3] Szklo A. S., Schaeffer R., Schuller M. E., Chandler W. Brazilian energy policies side-effects on $\mathrm{CO} 2$ emissions reduction. Energy Policy, 2005, Vol.33(3), pp.349-364.

[4] Quijera, J. A., Alriols, M. G., Labidi, J., Integration of a solar thermal system in a dairy process. Renewable Energy,( 2011) Vol. 36 (6), p. 1843-1853.

[5] Abbasi T., Abbasi S.A., 'Renewable' hydrogen: Prospects and challenges. Renewable and Sustainable Energy Reviews, 15 (2011) 3034-3040

[6] Armor J. N., The multiple roles for catalysis in the production of H2. Applied Catalysis A: General, 176 (1999) $159-176$

[7] Zeng K., Zhang D., Recent progress in alkaline water electrolysis for hydrogen production and applications. Progress in Energy and Combustion Science, 36 (2010) 307-326

[8] Lasia, A. Hydrogen evolution. In: Vielstich W, Lamm A, Gasteiger HA, editors. Handbook of fuel cell technology. John Wiley and Sons Ltd., p. 416, (2003).

[9] Birry, L.; Lasia, A. Studies of the hydrogen evolution reaction on Raney nickel-molybdenum electrodes. Journal Applied Electrochemistry, v. 34, p. 735-749, (2004).

[10] Dalla Corte D. A.,Torres C.,Correa P. S., Rieder E. S., Malfatti C. F., The hydrogen evolution reaction on nickelpolyaniline composite electrodes. International Journal of Hydrogen Energy, (2012) 1-8

[11] Herraiz-Cardona, I., Ortega, E., Vazquez-Gomez, L., Perez-Herranz, V., Double-template fabrication of threedimensional porous nickel electrodes for hydrogen evolution reaction. International Journal of Hydrogen Energy, 2012, vol. 37 (3), p. 2147-2156.

[12] Xie Z., He P., Du L., Dong F., Dai K., Zhang T. Comparison of four nickel-based for hydrogen evolution reaction. Electrochimia Acta, 2013, Vol. 88, pp. 390-394.

[13] Zaitseva,A.Y; Wilkinsona, D.S.; Weatherlya, G.C.; Stephensonb, T.F.; The preparation of highly porous structures from filamentary nickel powders. Journal of Power Sources 123 (2003) 253-260.

[14] Cengage Learning, Inc. High-strength powder metallurgy nickel-base resists corrosion (Metals Polymers Ceamics). Advanced Materials \& Processes, Jan, 2007, Vol.165(1), p.13(2) 